\title{
INFLUÊNCIAS E DETERMINAÇÕES PARA A OFERTA DA ESCOLARIDADE OBRIGATÓRIA NO BRASIL
}

\author{
Simone Fátima Flach \\ Universidade Estadual de Ponta Grossa - UEPG
}

\section{RESUMO}

Este estudo apresenta as influências e determinações de organismos internacionais na política educacional brasileira voltada para a escolaridade obrigatória no período compreendido entre os anos de 1970 e os primeiros anos de 2000. Tem por objetivo oferecer subsídios para a compreensão sobre como a ampliação da escolaridade ocorreu no período frente aos acordos e compromissos assumidos pelo governo brasileiro. Para alcançar tal objetivo apresenta as previsões para a escolaridade obrigatória, desde os Acordos MEC-USAID, ocorridos no final da década de 1960, até os encaminhamentos do Banco Mundial na década de 1990, os quais contribuíram para a configuração da escola obrigatória no início do novo século. Ao final, conclui que o arcabouço ideológico em circulação nas políticas educacionais em relação à educação obrigatória contribuiu tanto para o avanço quanto para expor os limites da organização educacional brasileira.

Palavras-chave: política educacional; escola obrigatória; educação brasileira.

\section{INFLUENCES AND GUIDELINES FOR THE PROVISION OF COMPULSORY SCHOOLING IN BRAZIL}

\begin{abstract}
This article presents the influences and guidelines of international organizations on Brazilian educational policies concerning compulsory schooling from the 1970s to the early years of 2000. The aim of the article is to provide elements to understand the increase in schooling that took place in the period mentioned in face of the treaties and commitments made by the Brazilian government. To this end the article presents the projections made about compulsory schooling since the Treaty MEC-USAID in the end of the 1960s until the guidelines proposed by the World Bank in the 1990s which contributed to the design of compulsory schooling in the beginning of the new century. The article demonstrates that the ideological framework present in the educational policies concerning compulsory schooling contributed not only for the advancement of Brazilian educational organization, but also to reveal its limitations.
\end{abstract}

Keywords: educational policy; compulsory schooling; Brazilian education.

\section{INTRODUÇÃO}

A política educacional brasileira tem sofrido, ao longo de sua história, diversas influências de educadores, países e de organismos internacionais. Acordos e compromissos tiveram o Brasil como signatário ao longo dos tempos, os quais visavam superar desigualdades e dificuldades no âmbito educacional e vincular a educação brasileira aos interesses dominantes do capitalismo mundial e ao projeto hegemônico de períodos específicos. É nesse contexto que o presente texto apresenta as influências e determinações de organismos internacionais nas alterações da política educacional brasileira para possibilitar a universalização e a ampliação do ensino fundamental. 
A política de ampliação do ensino fundamental, hoje situada no período de 9 anos de duração é resultado de inúmeros fatores históricos, políticos e sociais que se entrelaçam e colaboram para o pensamento sobre a questão. Elucidar tais fatores é imprescindível para entender que a duração da escolaridade obrigatória não é uma discussão recente e constitui-se nas contradições da história político-educacional brasileira. Para alcançar tal objetivo o texto apresenta as previsões para a escolaridade obrigatória no Brasil, desde os Acordos MEC-USAID ocorridos no final da década de 1960 até os encaminhamentos do Banco Mundial na década de 1990.

A oferta da escolaridade obrigatória esteve e está atrelada ao contexto econômico e político mundial. Esse atrelamento é visível em diversos momentos históricos. Foi o que aconteceu com o Acordo de Ponta Del Este e Santiago (conferência de Ponta Del Este ocorrida em 1961 e Conferência de Santiago ocorrida em 1962), quando o governo brasileiro se comprometeu a ampliar a oferta da educação obrigatória (ensino primário) para 6 anos de duração até o ano de 1970.

A Lei 4024/61 já apontava em seu texto a possibilidade de o ensino primário ter duração de 6 anos. Em 1962, foi elaborado pelo MEC e aprovado, pelo então Conselho Federal de Educação, o primeiro Plano Nacional de Educação, para um período de 8 anos, o qual procurava "atender a compromissos internacionais e crescentes demandas de um país em desenvolvimento" (PASQUALE, 1966, p. 18). Esse Plano tinha como uma das metas mais importantes o atendimento, até o ano de 1970, de $100 \%$ da população escolar de 7 a 11 anos.

No entanto, para alcançar as metas educacionais, a partir da década de 1960, o governo brasileiro realizou uma série de acordos que, de certa forma, foram determinantes na reconfiguração da organização da educação no país. Oferecer subsídios para a compreensão sobre como a ampliação da escolaridade ocorreu a partir dos anos de 1960 é a contribuição do presente estudo.

\section{A AMPLIAÇÃO DA ESCOLARIDADE E OS COMPROMISSOS MEC-USAID}

Devido à estrutura política e social existente, nos anos 1960, o sistema educativo brasileiro se caracterizava pela exclusão e seletividade. Nessa época ocorreu um processo de aproximação com os interesses internacionais através de acordos de cooperação técnica e assistência financeira prestados pela Agency for International Development, os quais ficaram conhecidos por Acordos MEC-USAID. Esses acordos foram realizados em caráter de sigilo, bem próprio do momento histórico vivido pelas agências americanas no contexto da guerra fria. Segundo Lima (1968, p. 8), no prefácio da obra Be-a-bá dos MEC-USAID "É a primeira vez, ao que se saiba, que o planejamento educacional de um país é objeto de sigilo para o próprio povo que o utilizará...”.

No período de 1964 a 1968 foram firmados 12 acordos que abrangiam desde a educação primária até o ensino superior. No entanto, o acordo que nos interessa é aquele firmado em 30 de dezembro de 1966, destinado especificamente ao Planejamento de Educação Primária no Brasil.

Baseados em aspectos como a transferência da responsabilidade direta da organização da educação do governo federal para os governos estaduais, prevista pela lei 4024/61, e a falta de experiência das autoridades estaduais na formulação e execução de planos educacionais, o Ministério da Educação e Cultura decidiu que o preparo das autoridades educacionais seria a condição necessária para a reformulação educacional em vista. Assim justificava-se a necessidade do referido acordo, o qual tinha como função 
essencial o preparo de técnicos para a formulação e execução de programas educacionais voltados para a educação primária. ( ALVES, 1968. p. 79).

$\mathrm{O}$ referido acordo tinha como fundamento estabelecer um projeto de cooperação entre o MEC e a USAID, o qual deveria atingir os seguintes objetivos:

- Contribuir em base nacional e estadual para a qualidade e eficácia da educação primária, elaborar e executar um plano específico para aumentar e aperfeiçoar o fluxo dos alunos pelo sistema educacional primário;

- Elaborar planos e ações específicas para o melhor entrosamento da educação primária com a secundária e superior;

- Melhorar os serviços regionais e nacionais no desenvolvimento e execução de programas eficazes de educação primária;

- Treinar uma equipe de técnicos brasileiros em planejamento, para a educação primária em nível nacional, capaz de dar assistência a regiões e Estados.

Segundo Lima (1968, p. 10) "o exame do texto dos acordos é mera diversão: tratando-se de um fenômeno de geopolítica, não tem grande importância o que está escrito, mas a própria política governamental". Nesse sentido, a forma como as ações são implementadas no contexto da prática educacional se torna relevante para a análise da educação e não, fundamentalmente, o que está definido nos documentos oficiais. Por isso, o delineamento das políticas educacionais que ocorreu após os Acordos se mostra importante para a análise da ampliação da escolaridade obrigatória em um país, cujos interesses governamentais nem sempre são explícitos.

Para o campo específico da educação primária, o segundo objetivo ("elaborar planos e ações específicas para o melhor entrosamento da educação primária com a secundária e superior"), se mostra extremamente importante, visto que poderia se constituir em importante aspecto tanto na garantia da educação obrigatória como possibilidade de sua ampliação.

Contudo, o que ocorreu foi a transformação do Estado em órgão captador de recursos, sendo uma das primeiras medidas a instituição, em 1964, do Salário Educação, que visava angariar recursos para o ensino primário. Esses recursos eram provenientes das empresas, as quais contribuíam financeiramente para os Fundos do Ensino Primário, tanto em nível estadual quanto nacional, devendo contribuir para a expansão do ensino primário.

Os acordos MEC-USAID tiveram ampla influência na organização da educação brasileira e foge do objetivo deste texto aprofundar seus impactos em todos os níveis, mas, sim, demonstrar como os acordos influenciaram a política nacional em relação à oferta da educação obrigatória. $\mathrm{O}$ que se evidenciou ao longo do período foi a criação de uma estrutura de sustentação para a reforma educativa em todo o sistema educacional brasileiro, a qual culminou com a Reforma do Ensino Superior, através da Lei 5540/68 e a reforma do $1^{\circ}$ e $2^{\circ}$ graus, através da Lei 5692/71.

No contexto das Reformas dois importantes relatórios se mostraram relevantes Relatório Meira Matos e Relatório do Grupo de Trabalho da Reforma Universitária - os quais demonstraram a necessidade emergente de reformulação de toda a estrutura educacional brasileira e em especial o modelo existente de educação primária e média (ROMANELLI, 1986, p. 233). Segundo essa autora, os Acordos MEC-USAID enfocavam a necessidade de integração entre as escolas primária e média, propondo-se que a escolaridade fosse estendida eliminando a fragmentação entre os dois níveis até então existentes. Dessa forma estaria criada a necessidade de uma reorganização da escola fundamental através da fusão entre os dois níveis. Por outro lado os relatórios brasileiros defendiam a reformulação do ensino médio em consonância com as necessidades do ensino 
superior, que se centrava na contenção do excedente e na profissionalização anterior ao ingresso na universidade.

O último acordo MEC-USAID foi firmado em 1968, mas as influências não findaram pois, conforme nos esclarece Buffa (1977, p. 141) "Independentemente da assinatura de novos acordos, a influência norte-americana na educação brasileira continuou a existir, mesmo porque as relações de dependência entre países são fundamentalmente determinadas pelas relações econômicas."

As contradições evidenciadas nos acordos realizados e nos relatórios citados estiveram presentes no texto da Lei 5692/71, a qual, além de reformular toda a oferta do ensino médio, através da profissionalização, reformou substancialmente a oferta do ensino primário e ginasial existente, instituindo o ensino de $1^{\circ}$ grau. Esse nível se mostra central no processo de discussão da ampliação da escolaridade obrigatória.

A escolaridade obrigatória foi ampliada de 4 para 8 anos através da fusão do antigo ensino primário com o ensino ginasial, instituindo-se o $1^{\circ}$ grau, e a faixa etária atendida ampliada dos 7 aos 14 anos.

Essa ampliação tem sérias implicações, pois compele o Estado a um acréscimo de suas obrigações com relação à educação do povo e supõe uma modificação estrutural profunda na educação elementar, já que a expansão do ensino decorrente disso imporá naturalmente um grau de elasticidade e capacidade de adaptação à realidade inexistentes em nossos tradicionais cursos primário e ginasial.( ROMANELLI, 1986. p. 237)

Procurando ajustar as diferenças existentes entre os ensinos primário e ginasial, o ensino de $1^{\circ}$ grau caracterizou-se como um amplo projeto cultural que adaptou o ensino às demandas políticas e sociais da época e aos interesses dos grupos hegemônicos. (SOUZA, 2004, p. 153).

Os compromissos educacionais relativos à ampliação da escolaridade, no período militar, demonstram articulação estreita com a necessidade de preparo de quadros específicos para o projeto econômico-produtivo em marcha, pautado na contenção da demanda por vagas no ensino superior.

A tentativa de uniformização e ampliação da oferta da escola obrigatória mostrouse frustrada, visto que a ruptura existente entre o primeiro e o segundo segmento (primário e ginásio) permaneceu sem grandes possibilidades de articulação tanto interna quanto externamente. Internamente, a escola permaneceu dividida em diversos aspectos: organização curricular, formação de professores, clientela atendida e, muitas vezes, em relação aos espaços institucionais para a oferta. Externamente, as políticas educacionais empreendidas a partir da Lei 5692/71 não foram capazes de realizar a articulação tão necessária para que o ensino de $1^{\circ}$ grau se constituísse em um todo único e realmente obrigatório, permanecendo na prática a fragmentação entre as séries iniciais e finais.

Ao término do governo militar em meados dos anos 1980, houve a manutenção do modelo educacional até então existente, mas os debates empreendidos no campo social e político, além da participação do país nos encontros internacionais sobre a situação educacional mundial impulsionaram novas possibilidades para reorganização das políticas sociais em curso.

Algumas medidas tomadas, principalmente a partir da década de 90, aprofundaram, em alguns contextos (como no Estado do Paraná) a ruptura até então existente, não possibilitando que a ampliação da escolaridade obrigatória fosse usufruída efetivamente pela populaçãoi . A oferta do ensino fundamental, fragmentada por diferentes entes da 
esfera pública, pode ser apontada com um dos motivos que legitima o não acesso ao todo e a não conclusão da etapa, pois não há continuidade de ações que priorizem a permanência do aluno na escola. Assim, a substituição do ensino de $1^{\circ}$ grau, previsto na Lei 5692/71, pelo ensino fundamental, através da Lei 9394/96, herdou a desarticulação ainda existente nessa etapa da educação básica, não sendo capaz de torná-lo um todo realmente obrigatório.

\title{
A ESCOLA OBRIGATÓRIA E A EDUCAÇÃO PARA TODOS:
}

Em relação à reconfiguração do modelo educacional brasileiro pós-ditadura militar, em especial em relação ao direito à educação e ampliação da escolaridade obrigatória, é importante a análise sobre as influências das Agências Internacionais na delimitação de políticas públicas para o setor educacional nos países periféricos, como é o caso do Brasil.

Tais influências estão na esteira do ideário comprometido com o desenvolvimento do processo de internacionalização do capital, também denominado de globalização da economia. Tomamos como recorte para o desenvolvimento de tal ideário as propostas chegadas a termo no conhecido encontro realizado em 1989, nos Estados Unidos, cujas conclusões ficaram conhecidas como "Consenso de Washington".

O objetivo da reunião, que contou com a presença de membros dos organismos de financiamento (FMI, BID, Banco Mundial), funcionários do governo americano e economistas latino-americanos, segundo Marcelo Dias Carcanholo (2002), era avaliar as reformas econômicas empreendidas na América latina. O mesmo autor afirma que as deliberações da referida reunião serviram de diretrizes para atuação de seus participantes.

As orientações do Consenso de Washington estão ligadas à redução do Estado e à abertura dos mercados em nome da concorrência que estimule produtividadecompetitividade.

As influências do ideário comprometido com a produtividade-competitividade se mostraram presentes no campo educacional de tal forma que o governo brasileiro assumiu esse pensamento, definindo a partir dele as políticas públicas para o setor educacional a partir dos anos de 1990.

\begin{abstract}
Mecanicamente - e repetindo a velha máxima salvacionista -, atribuiu-se à educação o condão de sustentação da competitividade nos anos de 1990. Vasta documentação internacional, emanada de importantes organismos multilaterais, propalou esse ideário mediante diagnósticos, análises e propostas de soluções consideradas cabíveis a todos os países da América Latina e Caribe, tanto no que toca à educação quanto à economia. Essa documentação exerceu importante papel na definição de políticas públicas para a educação no país. (SHIROMA, 2000, p. 56).
\end{abstract}

Um importante documento que influencia a educação brasileira a partir da década de 1990 foi a Declaração Mundial de Educação para Todos, elaborada a partir da Conferência Mundial de Educação realizada em março de 1990 em Jomtien, na Tailândia. Esse evento foi marcado pela participação de governos, agências internacionais, organismos não governamentais, associações profissionais e autoridades educacionais provenientes do mundo inteiro. Os 155 países (dentre os quais o Brasil) que subscreveram a Declaração assumiram o compromisso de garantir a educação básica de qualidade para todas as pessoas (crianças, jovens e adultos). 
Segundo Torres (2000a) a Conferência de Jomtien serviu de marco para o desenvolvimento e execução de políticas públicas para a educação na década de 90 nos países em desenvolvimento.

A Declaração Mundial de Educação para Todos, em seu preâmbulo lembra a Declaração Universal dos Direitos Humanos, afirmando a educação enquanto direito de todos e enumera, apesar dos esforços empreendidos, a perpetuação de algumas desigualdades: mais de 100 milhões de crianças, das quais 60 milhões do sexo feminino, sem acesso à educação primária; 960 milhões de adultos analfabetos; mais de 100 milhões de crianças e incontáveis adultos que não conseguiam concluir o ciclo básico, e outros milhões, apesar de concluí-lo, não conseguiam adquirir conhecimentos e habilidades essenciais.

Pautados nesse quadro, no mínimo complicado, os nove países com maior taxa de analfabetismo do mundo ${ }^{\mathrm{ii}}$, foram levados a desencadear uma série de ações para o atendimento das deliberações da Conferência.

O documento da Declaração, o qual, em linhas gerais, manifesta a intenção de satisfazer as necessidades básicas de aprendizagem da população mundial, em especial aquelas excluídas no e do processo educativo. Segundo a Declaração, os problemas como aumento da dívida dos países ameaçam de estagnação e decadência econômicas; aumento da população, diferenças econômicas entre as nações, a guerra, a ocupação, as lutas civis e a degradação do meio ambiente impedem ou dificultam os avanços da educação básica em muitos países.

Como a deterioração da educação se mostrou marcante em muitos países na década de 1980, e a chegada do novo século é considerada no documento como possibilidade de novas esperanças. O documento remete a uma visão romanceada da educação onde todos são conclamados a colaborar na melhoria das condições de aprendizagem da população mundial.

Torres (2000b), ao realizar uma análise dos compromissos assumidos na Declaração e as ações implementadas na primeira metade da década de 90, alerta que tais ações desenvolvidas a partir dos anos 90 não foram lineares nem homogêneas, ocorrendo variações entre países e em seu interior. A autora apresenta alguns dados do Fórum Consultivo realizado em 1996, o qual expõe que: a matrícula escolar nos países em desenvolvimento cresceu em 50 milhões de alunos, em um ritmo duas vezes maior do que na década anterior; de 128 milhões de crianças fora da escola em 1990 se havia passado para 109 milhões em 1995; a matrícula escolar continuou desce em vários países, o que foi justificado devido à retração do crescimento populacional e regularização da idade dos alunos dentro do sistema educativo.

Mas, a mesma autora alerta que, apesar dos avanços, alguns desafios permaneciam, visto que a escolaridade para todos foi entendida como equivalente da educação primária universal e o acesso à escola como mais importante que a própria aprendizagem, ocorrendo ênfase na quantidade em detrimento da qualidade; devido a problemas conceituais, a visão ampliada de educação básica foi aplicada de maneira seletiva, havendo um esforço para incrementar a matrícula na educação primária, sem a devida atenção à educação para jovens e adultos e o atendimento à educação infantil. Dessa forma, mesmo as agências internacionais, organizadoras da Conferência Mundial em Jomtien, não estiveram em consenso sobre o conceito de visão ampliada de educação e de educação básica.

Nesse sentido, não é difícil entender as incoerências e contradições existentes na interpretação dos governos signatários da Declaração de Educação para Todos, inclusive as interpretações ocorridas no âmbito da política educacional brasileira. Apesar das contradições conceituais, a Conferência teve o mérito de colocar o tema educativo no 
centro das atenções, chamando a atenção mundial para a importância e prioridade da educação de forma geral e da educação básica em particular. (TORRES, 2000b).

A Declaração Mundial de Educação Para Todos procura redefinir o conceito de educação básica, definindo-se como prioritária a educação primária e para cumprir o compromisso de universalizá-la, os governos devem envolver outros segmentos sociais que não apenas a escola, ou seja, outras instituições como família, comunidade, meios de comunicação, etc.

Os compromissos assumidos pelo governo brasileiro em relação à Conferência de Jomtien e em relação à escolaridade obrigatória se inscrevem no conceito de educação básica colocado na Declaração, ou seja, a ampliação da visão de educação básica. Essa foi entendida nos anos posteriores como a ampliação do tempo escolar, seja em número de anos, dias letivos e permanência dos alunos no contexto escolar em situações de "suposta" aprendizagem.

Sem retirar a importância dessas medidas em um contexto em que o acesso à escola sempre foi limitado devido às deficiências internas e externas ao sistema educativo, o compromisso de universalizar a educação básica no contexto brasileiro ficou entendido como a necessidade de democratizar o ensino fundamental.

Alguns indicadores citados por Rosa Maria Torres sobre a década da Educação para Todos em diversos países, inclusive no Brasil revelam ações onde predominam enfoques limitados à garantia do direito à educação e em especial à educação obrigatória. Assim, selecionamos os seguintes indicadores:

- Predominância de enfoque quantitativo, com ênfase no acesso e matrícula da escola primária: esse indicador revela que o direito à educação proclamado se limita apenas ao acesso, sem um trabalho mais efetivo no sentido de garantir a aquisição de conhecimentos necessários em uma vida cidadã; convém ressaltar que a universalização do acesso à escola não significa, necessariamente, a universalização da aprendizagem;

- Ênfase na educação primária com 4 anos de duração revelando compromissos assumidos pelos países, os quais se limitaram à universalização da educação primária em uma visão estreita de educação, a qual se limita ao espaço e currículo escolar já estabelecido.

Esses dois indicadores selecionados demonstram o quão estreitos poder ser os encaminhamentos políticos utilizados pelos governos e agências internacionais para atender os dispositivos da Declaração Mundial de Educação para Todos.

No entanto, mesmo se distanciando do pressuposto de universalização do acesso à escola, durante a década de 1990 alguns países da América Latina e Caribe estenderam o tempo de duração da escolaridade obrigatória, agregando ora a educação imediatamente superior ora a inferior àquela já prevista, conforme apresentado a seguir. 
QUADRO 1 - DURAÇÃO DA ESCOLARIDADE OBRIGATÓRIA NA DÉCADA DE 1990 - AMÉRICA LATINA E CARIBE

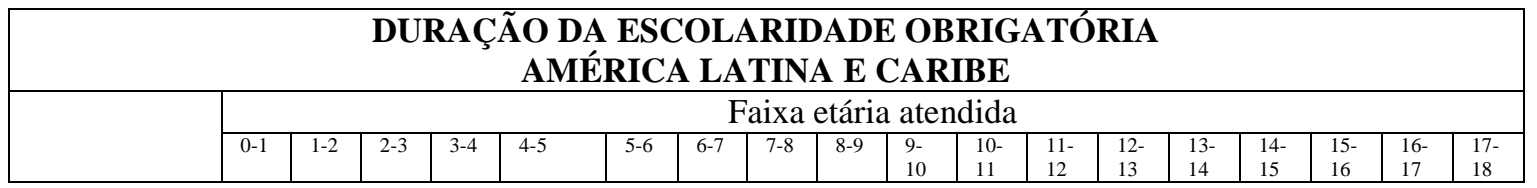

\begin{tabular}{|c|}
\hline México \\
9 anos
\end{tabular}

\begin{tabular}{|c|}
\hline El Salvador \\
11 anos \\
\hline
\end{tabular}

\begin{tabular}{|c|}
\hline Argentina \\
10 anos
\end{tabular}

Bolívia

9 anos

\begin{tabular}{|c|}
\hline Equador \\
10 anos \\
\hline
\end{tabular}

Brasil

8 anos

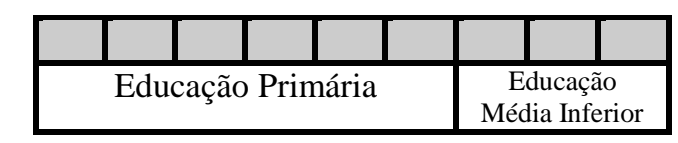

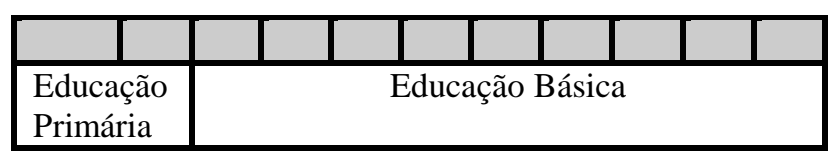
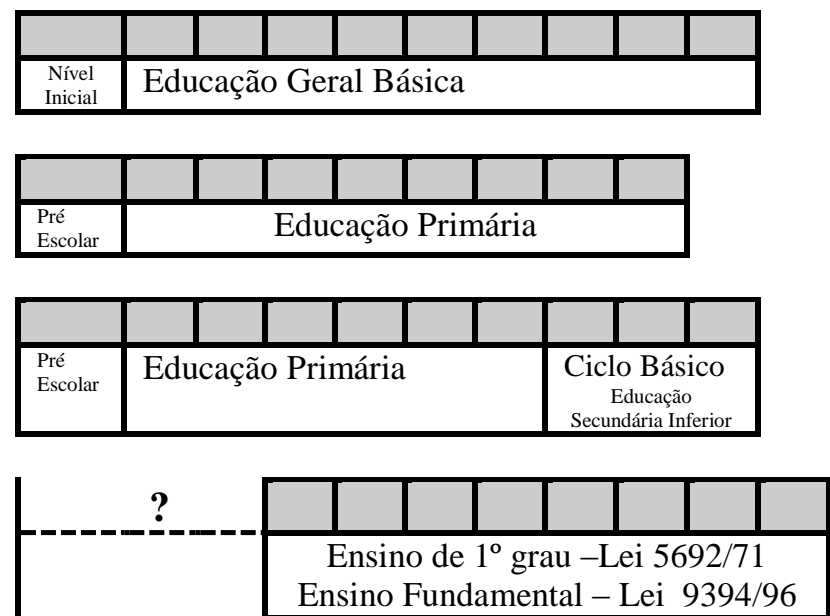

Fonte: TORRES, Rosa Maria.Una década de Educación para Todos: La tarea pendiente. Buenos Aires: UNESCO, 2000. (organizado pela autora)

O que podemos inferir do quadro apresentado é que o Brasil, em linhas gerais não realizou mudanças substanciais em relação à oferta da educação obrigatória já existente, visto que o ensino obrigatório já era previsto com duração de 8 anos, sendo alterada apenas a sua nomenclatura a partir da Lei 9394/96. A estratégia brasileira de alteração da denominação da escolaridade obrigatória, sem efeitos práticos de ampliar seu entendimento e duração, demonstra o quão distante a política educacional brasileira ficou dos demais países latino-americanos.

Apesar de se mostrar como indicador importante da melhoria do desempenho dos alunos, o número de horas ou de dias em que os mesmos se mantêm na escola, as formas muito díspares de organização da educação na América Latina e Caribe impedem comparações entre os diversos sistemas. Em análise realizada na primeira metade da década de 90, Torres (2000b) alerta para as formas que a ampliação da escolaridade obrigatória assumiu nos contextos diferenciados, em especial nos países em desenvolvimento, os quais a utilizaram como ampliação do tempo escolar, seja através da ampliação dos anos de escolaridade quanto o prolongamento do ano escolar e o aumento das horas de estudo, dentro e fora da escola ${ }^{\text {iii }}$.

No Brasil a questão da educação básica e da educação para todos assumiu conotação contraditória, pois havia discussão sobre a educação básica ser considerada desde a infância até o término do ensino médio. Inclusive a LDBEN, Lei 9394/96, validou o entendimento de que a educação básica compreende a educação infantil, ensino 
fundamental e ensino médio. Caso toda a educação básica fosse considerada obrigatória haveria uma ampliação dos então 8 anos de duração para até 17 anos, quando o jovem concluiria esse nível de ensino. No entanto, a adoção dessa possibilidade mostrou-se impossibilitada por motivos de ordem estrutural, financeira e pedagógica.

Todavia, parece-nos pacífico afirmar que a Declaração Mundial de Educação para Todos encontrou solo fértil no meio educacional brasileiro, visto que as bases tanto políticas quanto ideológicas lançadas por aquele documento serviram de mola propulsora para uma série de debates e estudos realizados no Brasil. As ações governamentais estiveram, em grande parte, voltadas para o ideário defendido na Declaração de Jomtien, além dos pressupostos que estiveram presentes no debate de tramitação dos Projetos de LDB no Congresso Nacional no período respectivo.

Um movimento que se mostrou importante nesse debate foi aquele capitaneado pelo MEC e que culminou na publicação do Plano Decenal de Educação para Todos, em 1993. Segundo Shiroma, Moraes e Evangelista (2000, p. 62), “com esse plano, o Brasil traçava as metas locais a partir do acordo firmado em Jomtien e acenava aos organismos multilaterais que o projeto educacional por eles prescrito seria aqui implantado."

O Plano Decenal de Educação para Todos sinalizou explicitamente em seu texto a anuência do governo brasileiro em relação ao cumprimento das metas definidas em Jomtien. Em termos práticos, os ditames do Plano Decenal de Educação para Todos centraram-se no Ensino Fundamental, visto ser esse o nível da escolaridade que demonstra obstáculos mais prementes a serem enfrentados, conforme expresso no documento:

São muitos os obstáculos e desafios a serem enfrentados na educação fundamental. Embora a consciência social de sua importância venha se ampliando de modo significativo, a educação básica não adquiriu, ainda, o status de questão nacional premente e de item prioritário da agenda política, seja dos poderes públicos, seja das elites, das famílias e dos vários segmentos sociais. Somam-se a isso os obstáculos próprios do sistema educacional brasileiro, cujas características de desempenho e de insucesso escolar comprometem os avanços obtidos nas últimas décadas nos níveis de atendimento educativo da população. (BRASIL, 1993, p. 31)

Em linhas gerais, o Plano Decenal de Educação para Todos reconheceu a incapacidade do sistema educacional brasileiro em garantir o acesso e a permanência com qualidade e igualdade, visto a existência de profundas desigualdades sociais e culturais.

$\mathrm{Na}$ tentativa de superar as dificuldades existentes, o documento enumera algumas estratégias a serem utilizadas para a universalização do ensino fundamental, naquele momento entendido como o nível prioritário para as ações político-educacionais a serem desenvolvidas. Em relação às estratégias o documento apresenta os objetivos gerais do desenvolvimento da Educação Básica, Metas Globais e Linhas de Ação Estratégica.

Nas Metas Globais o documento estabelece alguns objetivos a serem alcançados em 10 anos. Em relação ao direito à educação obrigatória, podemos enumerar os seguintes:

- Incrementar, em cerca de 50\%, os atuais níveis de aprendizagem das matérias do núcleo comum, tomando como referência os novos padrões de conteúdos mínimos nacionais e de competências básicas a serem nacionalmente determinadas com a participação dos sistemas de ensino;

- Elevar a, no mínimo, 94\% a cobertura da população em idade escolar; 
- Assegurar a melhoria do fluxo escolar, reduzindo as repetências, sobretudo na $1 \mathrm{e}$ 5 séries, de modo a que $80 \%$ das gerações escolares possam concluir a escola fundamental com bom aproveitamento, cumprindo uma trajetória escolar regular;

- Criar oportunidades de educação infantil para cerca de 3,2 milhões de crianças do segmento social mais pobre;

- Dotar todas as escolas de ensino fundamental, urbanas e rurais, estaduais de municipais, de condições básicas de funcionamento.

A importância e a vinculação do Plano Decenal de Educação para Todos ao ideário dos organismos internacionais é incontestável, dado o status ao qual o documento é elevado e a forma como a sociedade é chamada para se responsabilizar pelas ações a serem empreendidas:

O desenvolvimento que se pode imprimir à educação básica depende da importância que a Sociedade Civil e o Estado atribuam ao projeto educacional do País. Torna-se, assim, necessária a criação de espaços para que todos os movimentos organizados, associações de pais e exalunos, grupos empresariais e sindicatos possam contribuir e desempenhar um papel ativo na melhoria da educação oferecida em todo o País. (BRASIL, 1993, p. 44).

Tendo em vista o reconhecimento dos problemas internos do sistema educacional brasileiro, o acesso e a permanência com sucesso no âmbito escolar mostra-se fundamental para o conseqüente avanço aos níveis mais elevados de ensino. Nesse sentido o Plano Decenal de Educação para Todos assim se posiciona em uma das linhas estratégicas de ação:

Do conjunto de esforços sobre a oferta de ensino, a permanência com sucesso na escola talvez constitua o maior desafio a ser enfrentado neste final de século, pois, além de elevar o nível de produtividade escolar, terá amplo impacto sobre o acesso. O desenvolvimento de medidas de melhoria da qualidade da iniciação escolar (quatro séries iniciais), associado a avanços resultantes de programas curriculares inovadores, permitirá ganhos progressivos no fluxo escolar. (BRASIL, 1993, p. 47)

Outra questão que se sobreleva no Plano Decenal, perspectiva assumida na Declaração Mundial, é o atendimento focalizado para crianças em situação de exclusão social (rurais, pobres, indígenas, trabalhadoras) visando incluí-las no processo educacional.

O Plano Decenal de Educação para Todos, publicado em 1993, traçava metas globais para a educação brasileira e demonstrava perfeito acordo com o projeto educacional prescrito pelos organismos internacionais. Essa consonância será vislumbrada em diversos documentos internacionais e na organização da educação brasileira em curso na época.

\section{A ESCOLA OBRIGATÓRIA NAS ORIENTAÇÕES DA CEPAL}

Participante da Conferência Mundial de Educação para Todos, a CEPAL Comissão Econômica para a América Latina e Caribe, também exerceu grande influência no processo de reformas educativas para a educação obrigatória para os países em desenvolvimento. Suas orientações estavam circunscritas ao âmbito da reestruturação produtiva, na qual os sistemas educativos estariam consonância com o sistema produtivo ${ }^{\text {iv }}$. 
No documento Educación y conocimiento: eje de la transformacion productiva con equidad, a CEPAL/UNESCO defende que os países devem enfrentar os desafios hodiernos (cidadania e competitividade) com uma necessária reforma do sistema produtivo e difusão de conhecimentos. Através dessas ações, os países estariam aptos a alcançar uma progressiva equidade social. Para tanto, seria fundamental uma profunda revisão dos conteúdos cognitivos, instrumentais e éticos da formação proporcionada pela sociedade às novas gerações. Ou seja, seria necessária uma reforma educativa que possibilitasse o ingresso dos países menos desenvolvidos na dinâmica capitalista dos mais desenvolvidos.

O documento expressa ainda dois objetivos estratégicos a serem alcançados, os quais traduzem interesses comprometidos com a acumulação capitalista em marcha: a construção da moderna cidadania e a competitividade internacional dos países.

Para tanto, os cidadãos devem ser formados em uma consciência de responsabilidade social, ou seja, solidários e ativos para assumirem tarefas como membros de uma organização com um projeto comum. Os sistemas educacionais têm, assim, o desafio de distribuir equitativamente os conhecimentos e o domínio dos códigos necessários para a participação cidadã, formar as pessoas nos valores e princípios éticos e desenvolver suas habilidades e competências para conseguir um bom desempenho nos diversos âmbitos da vida social.

Para atingir tais objetivos, segundo o documento, as políticas devem atender a critérios norteadores de equidade e desempenho. A equidade, no documento aqui analisado, é entendida como igualdade de oportunidades, compensação das diferenças, desenvolvimento equilibrado e coesão do corpo social em seu conjunto. Assim, a equidade deve ser entendida não como sinônimo de igualdade, mas atendimento diferenciado às necessidades diferenciadas.

Na perspectiva defendida pela CEPAL, o Estado deve ser o elo na relação entre o sistema produtivo e educativo, fixando metas, avaliando o desempenho e usando incentivos para aumentar a eficácia e equidade do sistema. Com esse entendimento, as demandas passariam a ser atendidas conforme as necessidades e prioridades do mercado.

De acordo com os pressupostos defendidos pelo documento, a efetivação das políticas educacionais deve atingir alguns objetivos essenciais:

- Gerar uma institucionalidade do conhecimento aberta aos requisitos da sociedade,

- Assegurar o acesso universal aos códigos culturais da modernidade;

- Impulsionar a criatividade no acesso, difusão e inovação científico-tecnológicos;

- Propiciar uma gestão institucional responsável;

- Apoiar a profissionalização e o protagonismo dos educadores;

- Promover o compromisso financeiro da sociedade com a educação;

- Desenvolver a cooperação regional e internacional.

Em relação direta com a ampliação da escolaridade obrigatória, quando o documento trata sobre o objetivo de assegurar o acesso universal aos códigos culturais da modernidade propõe a expansão de programas de educação pré-escolar para crianças a partir dos cinco anos de idade, através de duas maneiras: ampliar a educação obrigatória para crianças nessa faixa etária, no nível pré-escolar; e empreender ampla campanha de sensibilização e propaganda orientada para que os pais matriculem seus filhos na mais tenra idade. Todavia, o documento reconhece que essas medidas requerem maior capacidade de cobertura dos sistemas de ensino para o atendimento da demanda, principalmente nas localidades de baixa cobertura.

Ainda, para atender o objetivo acima mencionado o documento propõe reorganização curricular e dos métodos pedagógicos a serem utilizados, para evitar níveis elevados de fracasso escolar. Nessa perspectiva, para a reorganização curricular há 
sugestão explícita de adoção de ciclos de aprendizagem, de forma a adaptar os currículos ao ritmo de aprendizagem de cada aluno.

O documento Educación y conocimiento: eje de la transformacion productiva con equidad fixa, em linhas gerais, orientações que se mostram fortes no estabelecimento de políticas educativas: centralidade do conhecimento, equidade, qualidade e novas formas de gestão (onde a descentralização exerce papel de destaque).

Mesmo que a tese defendida pelo documento esteja se mostrando supostamente articulada com as necessidades sociais, não podemos deixar de refletir sobre os interesses contidos nas entrelinhas de um documento muito bem organizado e que procura demonstrar preocupação com o desenvolvimento dos países latino americanos.

Não resta hoje qualquer dúvida de que o mundo moderno exige conhecimentos mais amplos do que no passado, elevando a demanda por maior qualificação média não apenas da força de trabalho, mas de todos os membros da sociedade considerada. Exige também conhecimentos diferentes, na medida em que novas tecnologias são introduzidas no cotidiano, sem qualquer chance de escape por parte dos que estejam integrados ao mercado (mesmo que marginalmente); sua utilização supõe o domínio de novas técnicas e novos conteúdos. A consciência de tais exigências objetivas vinda do âmbito objetivo da produção e do consumo põe uma pá de cal sobre a discussão que atravessou décadas a respeito de se a evolução do capitalismo conduzia à qualificação ou à desqualificação da força de trabalho. No Terceiro mundo, ela desqualifica a ideia de uma educação sem conteúdos, em nome do respeito à cultura da pobreza ou ao folclore. Mais do que nunca, essa sociedade tem como condição primeira o letramento, embora ele seja claramente insuficiente para enfrentar os novos tempos.( PAIVA, 1994. p. 23)

O deslocamento da discussão no setor educacional da quantidade para a qualidade, da aprendizagem para o conhecimento, do centralismo para a descentralização, da igualdade para a equidade, fortalece o ideário que vincula a implementação de políticas públicas voltadas para os interesses do mercado produtivo sem a justa consideração pelas necessidades da maioria da população, principalmente em relação aos mais pobres.

As estratégias recomendadas pela CEPAL, e reafirmadas por outros organismos multilaterais influenciaram e influenciam as políticas para o setor educativo, não só no Brasil, mas nos demais países latino-americanos. Isso demonstra a fragilidade da região às determinações gerais ditadas segundo interesses não totalmente explícitos e que supostamente visam o desenvolvimento desses países.

\section{AS INFLUÊNCIAS DA UNESCO: (COM) PARTILHAR A EDUCAÇÃO}

As contribuições da Organização das Nações Unidas para a Educação, a Ciência e a Cultura - UNESCO mostram-se importantes para o delineamento das políticas educacionais na América Latina e Caribe, principalmente em relação às reformas educativas efetivadas a partir da década de 1990. Algumas ações lideradas pela UNESCO, em conformidade com a orientação de outros organismos multilaterais, ofereceram o sustentáculo necessário para o conjunto de reformas empreendidas e ainda em curso.

É importante ressaltar que a UNESCO se caracterizou, na década de 1980, como a única agência das Nações Unidas que atuava no continente na área específica da educação. 
A partir de 1990 a centralidade no oferecimento de apoio técnico e financeiro para os países da região foi assumida por outra agência: o Banco Mundial.

Na década de 1980 o Projeto Principal de Educação para a América Latina e Caribe (1981 - 2001) exerceu influência significativa nos encaminhamentos político-educacionais na região. Esse projeto surgiu devido à reivindicação e iniciativa dos Ministros da Educação e Ministros de Planejamento Econômico dos países da América Latina que participaram da Conferência Regional a eles destinada, realizada no México, no ano de 1979. As deliberações dessa Conferência foram apresentadas e aprovadas formalmente na Reunião Intergovernamental, realizada em Quito, em 1981, ficando oficialmente criado o Projeto Principal de Educação para a América Latina e Caribe.

Em 1981, quando aprovado o Projeto Principal de Educação para a América Latina e Caribe, os participantes da Reunião reconheceram alguns indicadores da problemática educacional latino-americana, tais como: baixa escolaridade da população, elevado percentual de adultos analfabetos, altos índices de evasão escolar, dentre outros, além de sistemas educativos centralizados.

Frente a essa situação, o Projeto Principal de Educação caracterizou-se como um planejamento político-educacional que teve como orientadores das ações a serem implementadas três objetivos principais:

- Assegurar educação a todas as crianças em idade escolar, com duração mínima de 8 a 10 anos, até o final de 1999.

- Eliminar o analfabetismo até o final do século e ampliar os serviços educacionais para os adultos; e

- Melhorar a qualidade e eficiência dos sistemas educativos através de reformas educacionais.

Segundo as palavras oficiais da UNESCO, o Projeto Principal de Educação marcou o início do desenvolvimento educacional na década de 80 , cujo desafio principal estava centrado na expansão da educação para a maioria da população, dando prioridade ao atendimento de grupos mais desfavorecidos e vulneráveis. Durante o período de vigência do Projeto, a cada dois anos os Ministros de Educação da região se reuniram para avaliar as ações do Projeto e discutir temas sobre política educacional. Foi realizado um total de 7 reuniões no período de 1981 - 2001, as quais ficaram conhecidas como PROMEDLAC.

A década de 1980 foi marcada pelo Projeto Principal, o qual procurava definir a aplicação de estratégias que atendessem, em curto prazo, os problemas conjunturais da região. Tais estratégias estavam devidamente articuladas com as políticas globais de desenvolvimento. (UNESCO, 1998).

A mudança de eixo nas ações da UNESCO nos anos de 1990 ocorre quando, vinculada ao movimento global, a centralidade é definida por grandes reformas educacionais que orientam para a transformação profunda do modelo educacional, tanto nos aspectos pedagógicos quanto institucionais nos diversos níveis do sistema. (UNESCO, 1998).

É nesse contexto que, em 1991, sob influência da Conferência de Jomtien, realizada em 1990, os objetivos do Projeto Principal são superados, sendo redefinidas suas metas e estratégias. Em reunião realizada em Quito, com a participação de 29 dos 33 estados membros, foi constatada em linhas gerais que a expansão da educação não foi acompanhada da melhoria da qualidade do ensino, sendo necessária uma transformação do sistema para alcançar maior qualidade com equidade.

Importante destacar que no início da década de 90 a região passava por um movimento crescente de processo democrático, devido ao término formal dos regimes autoritários. No contexto mundial, ao mesmo tempo, a queda do muro de Berlim, ocorrida 
em novembro de 1989 e o fim da União Soviética - URSS em dezembro de 1991 demonstravam a supremacia do sistema capitalista, influenciando significativamente no reordenamento político em todo o mundo. Esses fatos podem ser apontados como condição para a incorporação de novas ações nos Planos Nacionais de Educação e o redirecionamento dos objetivos do Projeto Principal em conformidade com os dispositivos da Declaração Mundial de Educação para Todos.

O estudo dos documentos da UNESCO não evidencia a ampliação da escolaridade para além do estabelecido em 1981 (duração mínima da escolaridade obrigatória de 8 a 10 anos); mas há indícios sobre possíveis intenções de ampliar o acesso à educação já existente. No entanto, o que fica evidente é a preocupação de ampliação através da parceria com a sociedade em geral delegando responsabilidades aos diversos setores e, dessa forma, induzindo o envolvimento dos países latino-americanos nas demandas do aparelho produtivo global.

\section{AS ESTRATÉGIAS DO BANCO MUNDIAL E A EDUCAÇÃO PRIMÁRIA}

A influência do Banco Mundial no delineamento de políticas sociais no contexto global se iniciou no período pós-segunda guerra mundial devido às finalidades de sua criação. No início, o Banco mundial visava o restabelecimento dos países destruídos pela guerra e, para tanto, caracterizou-se como uma instituição financiadora de projetos específicos. Após serem atingidos esses objetivos, os interesses do Banco Mundial voltaram-se para os países em desenvolvimento e que apresentavam elevado índice de pobreza. O alívio à pobreza passou a ser definido como o objetivo mais abrangente do Banco Mundial.(ARRUDA, 2000).

Assumindo, após a década de 1990, centralidade estratégica de influência no planejamento para o setor educacional dos países em desenvolvimento, o Banco Mundial mudou o eixo de atuação, de financiador para definidor de políticas para o setor educacional. Assim, seu papel foi determinante para a organização das políticas para o setor em diversos países em desenvolvimento.

O discurso de "melhoria da qualidade da educação" contribuiu e ainda contribui para o fortalecimento de tendências e ideologias que produzem ineficiência, má qualidade e desigualdade no sistema escolar. (TORRES, 2000a).

A reforma educativa para os países em desenvolvimento proposta pelo Banco Mundial a partir de 1995 demonstra vinculação com os interesses econômicos do capitalismo mundial, o qual pressupõe estreita ligação entre as demandas do setor produtivo requerendo trabalhadores mais flexíveis e que atendam rapidamente as necessidades daquele setor.

A educação é a pedra angular do crescimento econômico e do desenvolvimento social e um dos principais meios para melhorar o bemestar dos indivíduos. Ela aumenta a capacidade produtiva das sociedades e suas instituições políticas, econômicas e científicas e contribui para reduzir a pobreza, acrescentando o valor e a eficiência ao trabalho dos pobres mitigando as consequências da pobreza nas questões vinculadas à população, saúde e nutrição (BANCO MUNDIAL apud TORRES, 2000a).

Nesse sentido, o Banco Mundial propõe no documento Prioridades y estrategias para la educacion: estudo sectorial del Banco Mundial, de 1995, que os governos deem 
maior prioridade à educação básica. $\mathrm{O}$ conceito de educação básica assumido pelo Banco Mundial se refere especificamente à educação primária $+1^{\mathrm{a}}$ fase da educação secundária, a qual no Brasil equivale ao ensino fundamental de 8 anos, visto que o Ensino Fundamental de 9 anos só foi legalmente instituído após 2006 e a lógica da obrigatoriedade de mais um ano se insere na discussão de assegurar a educação pré-escolar, visando melhor desempenho no percurso escolar.

Para obter o máximo benefício para a sociedade em seu conjunto, a primeira prioridade da educação pública é que todos os estudantes adquiram as atitudes básicas. (BANCO MUNDIAL, 1995, p. 78). As "atitudes básicas" são aquelas que permitam ao indivíduo a atuação efetiva na sociedade, através do conhecimento e habilidades elementares, tais como: leitura, escrita e cálculo, tal qual previsto posteriormente na legislação educacional brasileira.

No Brasil a prioridade na educação básica ficou expressa nos textos legais, os quais colocaram o ensino fundamental no centro das políticas públicas para a educação, o elevando à condição de ensino obrigatório, vinculando recursos específicos para a sua manutenção e desenvolvimento.

Mesmo reconhecendo os avanços conquistados em relação ao acesso à escola nos países em desenvolvimento, o documento oficial do Banco Mundial expressa alguns problemas, sob os quais vai construir as indicações para a reforma educativa. Eis a situação apontada pelo documento:

a) possibilidade de que o número absoluto de crianças sem nenhuma educação aumente nos próximos 20 anos;

b) pouco mais da metade dos alunos terminam o ciclo primário;

c) possibilidade de que a alfabetização de adultos continue sendo um grave problema;

d) impulsionada pelos êxitos obtidos com o nível primário, a demanda por educação secundária e superior está aumentando com mais rapidez que a capacidade de muitos sistemas de educação;

e) a diferença de educação está se agravando entre os países da OCDE e as economias de transição da Europa Ocidental e Ásia.

Para resolver tais problemas, os quais podem ser sintetizados em questões de acesso, equidade, qualidade e redução do distanciamento entre as reformas educativa e econômica, o Banco Mundial propõe um conjunto de seis reformas, as quais consistem em dar mais prioridade à educação (básica), prestar mais atenção ao rendimento (controle); concentrar em maior medida e mais eficientemente a inversão pública na educação básica, assim como recorrer ao financiamento familiar para o ensino superior; prestar mais atenção à equidade; intensificar a participação familiar no sistema educativo; dar mais autonomia às instituições a fim de permitir uma combinação flexível de insumos educacionais.

Ao eleger a educação básica como prioritária, o Banco Mundial a vincula como eixo central dentre os fatores necessários para manter o crescimento econômico e aliviar a pobreza. No entanto, o Banco Mundial elege como o principal desafio a ser enfrentado na educação básica a questão da qualidade, visto que isso é determinado tanto pelas condições de aprendizagem quanto pelos resultados obtidos pelos estudantes. Assim, são indicadas quatro medidas que influenciam ou influenciarão na melhoria da qualidade educativa: estabelecimento de normas; prestação de apoio, através de insumos; estratégias flexíveis para a utilização dos insumos; e, vigilância de resultados. Essas medidas estão devidamente articuladas com os objetivos gerais da instituição.

A prestação de apoio através de insumos eficazes para a aprendizagem dos alunos, em especial no nível primário, indica a utilização de 5 fatores que combinados de forma eficaz, resultam em maior qualidade na aprendizagem. Esses fatores podem assim ser 
sintetizados: motivação para aprender, plano de estudos, professor, tempo de aprendizagem e ferramentas necessárias. Eis tais fatores:

- Motivação para aprender: as políticas educativas precisam corrigir um déficit familiar de apoio à aprendizagem das crianças, através de programas pré-escolares e escolares de saúde e de nutrição, oferecendo suplementos quando necessário. Esse fator caracteriza-se como discriminação positiva, através da qual se procura corrigir defasagens existentes. A educação pré-escolar é entendida como antecipação da escolarização como meio de evitar a possível falta de desempenho educativo, "economizando recursos que, de outro modo, seriam investidos em repetência, evasão e fracasso escolar." (TORRES, 2000a, p. 175).

- Plano de Estudos: estabelecimento de conteúdos curriculares a serem aprendidos e avaliados. A ênfase na educação primária deve centrar-se na aprendizagem da leitura, escrita e cálculo.

- Professor: o conhecimento docente tem relação estreita e direta com o rendimento dos alunos, por isso deve-se investir na formação em serviço.

- Tempo de aprendizagem: o tempo de permanência do aluno em situação de aprendizagem se relaciona sistematicamente com o seu rendimento, por isso o Banco Mundial indica a ampliação do tempo de aprendizagem através do prolongamento do ano escolarv ${ }^{v}$, flexibilização e adequação dos horários a fim de efetuar o ajustamento às condições climáticas, agricultura, feriados religiosos e desenvolvimento de tarefas domésticas dos alunos, além da atribuição de tarefas escolares para realização em casa.

- Ferramentas Necessárias/ Materiais de Ensino: ênfase na oferta de livros didáticos, computadores, pois estes demonstram efeito positivo no rendimento dos alunos.

Segundo o documento do Banco Mundial, o estabelecimento de normas e o apoio de insumos eficazes são medidas importantes para melhorar o nível de instrução, mas a sua utilização deve pautar-se na flexibilidade, considerando as necessidades locais.

Ao analisar a proposta do Banco Mundial para a educação dos países em desenvolvimento Rosa Maria Torres (2000a) aponta algumas limitações visto que a educação proposta é formulada por economistas a ser executada por educadores. Há uma distância entre o modelo proposto e a realidade educacional onde tal modelo será implementado. "O modelo educativo que nos propõe o Banco Mundial é um modelo essencialmente escolar, com duas grandes ausências: os professores e a pedagogia." (TORRES, 2000a, p. 139).

Essa crítica torna-se explícita nos seguintes pontos:

A educação passa a ser analisada com critérios próprios do mercado e a escola é comparada a uma empresa. O ensino resume-se a um conjunto de insumos (inputs) que intervêm na caixa preta da sala de aula - o professor sendo mais um insumo - e a aprendizagem é vista como o resultado previsível da presença (e eventual combinação) desses insumos. Cada insumo se valoriza em separado e é priorizado ou não em virtude de duas questões: sua incidência sobre a aprendizagem (segundo estudos empíricos que demonstrariam tal incidência) e seu custo. É sob estes parâmetros que é definido um conjunto de "avenidas promissoras" e "becos sem saída" para a reforma da escola de primeiro grau, priorizando, por exemplo, o livro didático (alta incidência e baixo custo) sobre o docente (alta incidência mas alto custo), a capacitação em serviço sobre a formação 
inicial, ou o livro didático sobre a biblioteca escolar. (TORRES, 2000a, p. 140).

Em relação à ampliação do tempo de instrução as estratégias brasileiras assumem organização contraditória. Considerando que a quantidade de tempo dedicado à aprendizagem tem efeito no rendimento escolar, a primeira estratégia para aumentar a quantidade do tempo de instrução é prolongar o ano escolar oficial e a segunda é prolongar o tempo de instrução através de tarefas escolares a serem realizadas em casa. No entanto, segundo Torres (2000a), a questão da ampliação do tempo escolar não é medida simples, pois requer uma reorganização em todo o sistema educativo, tais como: organização curricular, pedagógica, salarial, cultural, etc.

Prolongar o ano escolar - para se aproximar ao menos aos padrões
europeus colocados como referência - implica numa verdadeira
revolução em todas as ordens, que afeta todas as esferas da sociedade. A
menos que se adotem medidas integrais em todas as esferas (institucional,
trabalhista, salarial, curricular, pedagógica, cultural, etc.) nada poderá
garantir que mais tempo oficialmente normatizado resulte efetivamente
em mais tempo de instrução e num melhor uso do mesmo. Sem uma
reforma do currículo, dos métodos e dos estilos de ensino, mais tempo de
instrução pode significar unicamente mais tempo do mesmo ensino. Não
é tanto na quantidade como na qualidade das interações que se dão no
equipamento escolar e na sala de aula, especificamente, que existe a
possibilidade de uma aprendizagem relevante e efetiva. (TORRES,
2000a, p. 170).

Cabe o alerta em relação aos efeitos que a medida pode acarretar para os alunos no processo de ampliação do tempo de instrução. Assim, a ampliação da escolaridade obrigatória, seja através da ampliação do tempo diário de permanência do aluno na escola, ampliação do calendário escolar ou dos anos de estudo é matéria controversa e exige reflexões profundas sobre seu impacto na vida dos cidadãos.

\section{CONSIDERAÇÕES FINAIS}

Todo o arcabouço ideológico em circulação nas políticas educacionais em relação à educação obrigatória, desde a década de 1970 até os primeiros anos de 2000, contribuiu tanto para o avanço quanto para expor os limites da organização educacional brasileira. Alguns avanços podem ser apontados nesse contexto: educação obrigatória e gratuita, indo além da educação primária (4 anos) e alcançando o ensino fundamental ( 8 e 9 anos); vinculação mais efetiva dos recursos financeiros para a manutenção e desenvolvimento do ensino (através da Lei 9424/96 - FUNDEF), visto que essa vinculação já era prevista, mas não implementada; ampliação do tempo escolar de 180 para 200 dias letivos e de 720 para 800 horas de trabalho escolar; a preocupação, nem sempre explícita e coerente, com a melhoria do desempenho escolar dos alunos. Todavia, o mesmo arcabouço que contribui para tais avanços expôs os limites existentes no processo: desconsideração pela importância da educação infantil, seja através da redução de seu tempo de duração ou pela vinculação limitada de recursos para essa etapa; descontinuidade de ações para o e ensino médio; ampliação do tempo escolar sem a devida preocupação com a reorganização interna para o atendimento dos alunos no contexto ampliado, o que pouco contribuiu para a reorganização curricular e efetiva aprendizagem. 
Ao aderir às propostas e determinações de Organismos Internacionais, o poder público brasileiro inseriu-se no movimento global priorizando ações para a educação como um todo, mas, paralelamente fragilizou a possibilidade de efetivação da garantia ao direto à educação nos diversos níveis de ensino, colaborando para o surgimento de uma realidade em que os direitos assegurados são burlados pelas instituições que deveriam garanti-los. $\mathrm{O}$ contexto contraditório em que se insere a política educacional brasileira, e em específico a ampliação da escolaridade, é o resultado de um construto sócio-histórico sobre o direito de todos e o direito de alguns, criando dentro de um mesmo suporte jurídico-legal interpretações diferentes e divergentes que são aceitas pela sociedade em geral como naturais.

No entanto, essa suposta "naturalidade" ou "adesão" a interpretações divergentes sobre direitos e situações iguais, mas destinados a indivíduos que se situam em espaços diferentes na estrutura social nos leva a considerar que no contexto brasileiro existem direitos garantidos e direitos assegurados. Essa realidade cria espaços, instituições e situações diferenciadas para os indivíduos serem atendidos, contribuindo para que na divisão social existam "cidadanias" exercidas conforme o lugar ocupado pelo indivíduo na sociedade.

Para compreender a oferta da escolaridade obrigatória na atualidade é preciso inserir-se no debate sobre como o direito à educação é assegurado e garantido na sociedade brasileira de forma a explicitar como as instituições responsáveis estabelecem estratégias para garantir, ou não, educação para a totalidade da população. Essa é outra análise necessária...

\section{REFERENCIAS}

ALVES, M. M. Beabá dos MEC-USAID. Rio de Janeiro: Edições Gernasa, 1968.

ARRUDA, M. ONGs e o Banco Mundial: é possível colaborar criticamente? In: TOMMASI, L. de; WARDE, M. J.; HADDAD, S. O Banco Mundial e as políticas educacionais. 3 ed. São Paulo: Cortez, 2000.

BANCO MUNDIAL. Prioridades y estratégias para la educación: estudio sectorial del Banco Mundial., 1995.

BRASIL, MEC. Plano Decenal de educação para todos. Brasília: MEC, 1993 - versão acrescida.

BUFFA, E.; NOSELLA, P. A educação negada: introdução ao estudo da educação brasileira contemporânea. 2 ed. São Paulo: Cortez, 1997.

CARCANHOLO, M. D. Neoliberalismo e o Consenso de Washington: a verdadeira concepção de desenvolvimento do governo FHC. In: MALAGUTTI, M. L.; CARCANHOLO, R. A.; CARCANHOLO, M. D. (orgs). Neoliberalismo: a tragédia do nosso tempo. 3 ed. São Paulo, Cortez, 2002.

CEPAL/UNESCO. Educación y conocimiento: eje de la transformacion productiva con equidad. Santiago, 1992. 
LIMA, L. O. O. Prefácio. In: ALVES, Márcio Moreira. Beabá dos MEC-USAID. Rio de Janeiro: Edições Gernasa, 1968

PAIVA, V. (org). Transformação produtiva e equidade: a questão do ensino básico. Campinas, SP: Papirus: 1994.

PASQUALE, C.. O desenvolvimento do ensino primário e Plano Nacional de Educação. Centro Regional de Pesquisas Educacionais "Prof. Queiroz Filho". Série I. Estudos e Documentos. Vol. 4. MEC/INEP. São Paulo, 1966.

ROMANELLI, O. de O. História da Educação no Brasil (1930/1973), 8ª ed., Petrópolis: Vozes, 1986.

SHIROMA, E. O.; MORAES, M. C. M. de; EVANGELISTA, O. Política educacional. Rio de Janeiro: DP\&A, 2000

SOARES, M. C. C. Banco Mundial: políticas e reformas. In: TOMMASI, L. de; WARDE, M. J.; HADDAD, S. O Banco Mundial e as políticas educacionais. 3 ed. São Paulo: Cortez, 2000.

SOUZA, R. F. de. Lições da escola primária. In: SAVIANI, D. et al. O legado educacional do século XX no Brasil. Campinas, SP: Autores Associados, 2004.

TORRES, R. M. Melhorar a qualidade da educação básica? As estratégias do Banco Mundial. In: TOMMASI, L.; WARDE, M. J.; HADDAD, S. (orgs.) O Banco Mundial e as políticas educacionais. 3 ed. São Paulo: Cortez, 2000a.

Una década de Educación para Todos: La tarea pendiente. Buenos Aires: UNESCO, 2000b.

\footnotetext{
${ }^{\mathrm{i}}$ A implementação do FUNDEF induziu à municipalização dos anos iniciais agravando a ruptura entre anos iniciais e finais do ensino fundamental. Portanto, o ensino fundamental não se constitui, ainda em um todo único.

ii Bangladesh, Brasil, China, Egito, Índia, Indonésia, México, Nigéria e Paquistão.

iii Isso pode ser evidenciado na ampliação do ano letivo para os ensinos fundamental e médio no Brasil, quando o ano letivo passou de 180 para 200 dias letivos, além da exigência legal de 800 horas anuais e 4 horas diárias de efetivo trabalho escolar.

iv Em 1990 a CEPAL publicou o documento Transformación Productiva con Equidad e em 1992, juntamemente com a UNESCO, Educación Y Conocimiento: Eje de la Transformación Productiva con Equidad.

${ }^{v}$ A Lei 9394/96 ampliou a duração do ano letivo para o ensino fundamental de 180 para 200 dias letivos e de 720 para 800 horas de efetivo trabalho escolar. Também se insere nessa discussão a ampliação do tempo através da escola de tempo integral.
}

Recebido: $\quad$ março-13 Aprovado: agosto-14 